\title{
Longitudinal analysis of subjective well-being in preadolescents: The role of emotional intelligence, self-esteem and perceived stress
}

Journal of Health Psychology

I-14

(c) The Author(s) 2020

Article reuse guidelines:

sagepub.com/journals-permissions DOI: $10.1177 / 1359105320951605$ journals.sagepub.com/home/hpq

(S)SAGE

\author{
Lidón Villanueva', Vicente Prado-Gascó ${ }^{2}$ \\ and Inmaculada Montoya-Castilla ${ }^{3}$ iD
}

\begin{abstract}
Subjective wellbeing has been conceptualized as a person's cognitive and affective evaluation of their life. In this line, life satisfaction and somatic complaints may be outstanding indicators of well-being. The aim of this longitudinal study was to analyze the combined contribution of trait emotional intelligence, self-esteem and perceived stress to well-being. Participants were 381 pupils aged $12-16$ years (56.1\% female). Hierarchical regression models and a fuzzy-set qualitative comparative analysis (QCA) were conducted. Trait emotional intelligence, self-esteem and low perceived stress were related in the expected direction to life satisfaction and somatic complaints. Findings support a specific pathway to improve wellbeing in preadolescents.
\end{abstract}

\section{Keywords}

fsQCA models, life satisfaction, preadolescents, somatic complaints, well-being

\section{Introduction}

Subjective well-being has been defined as a person's cognitive and affective evaluations of his or her life (Diener et al., 2003). Thus, this concept includes a vast array of phenomena, including people's emotional responses, domain satisfactions, and global judgments of life satisfaction (Diener, 2009; Diener et al., 2009). To properly measure this concept then, diverse measures of both pleasant and unpleasant valence should be included, as well as short and long-term influences. Accordingly, somatic complaints, as the somatization of emotional deficits that cannot be explained by medical causes (Miers et al., 2007), may play the role of emotional responses of unpleasant valence (Villanueva and Górriz, 2014), as a complementary indicator to life satisfaction, a very-well known pleasant valence index of well-being. In this work, a cognitive component (life satisfaction) and an affective component (emotional reactions reflected in somatic complaints) will therefore be analyzed.

\footnotetext{
'Department of Developmental, Educational, Social Psychology and Methodology, Universitat Jaume I, Castellón, Spain

${ }^{2}$ Social Psychology Department, Faculty of Psychology, Universitat de València, Valencia, Spain

${ }^{3}$ Department of Personality, Assessment and Psychological Treatment, Faculty of Psychology, Universitat de València, Valencia, Spain

All authors contributed equally to this work.

Corresponding author:

Vicente Prado-Gascó, Social Psychology Department, Faculty of Psychology, University of Valencia, Avenida Blasco lbañez 21, Valencia, 46010, Spain.

Email: vicente.prado@uv.es
} 
Undoubtedly, the best-known component of subjective well-being is life satisfaction. This concept implies a conscious cognitive evaluation of one's life that depends on a comparison of life circumstances to one's standards (Pavot and Diener, 1993). Most human beings appear to experience a moderately positive level of life satisfaction as a type of adaptive human mechanism to maintain reasonable living conditions and avoid depression (Cummins and Nistico, 2002).

In addition to the cognitive aspect of subjective well-being, the absence of a detectable organic cause of somatic complaints has emphasized the role of emotional factors (Miers et al., 2007). The prevalence of somatic complaints is a serious problem, accounting for $4 \%$ of children's visits to pediatric services in primary care (Sánchez and Barrio, 2012) and over 20\% of adolescents experiencing multiple physical symptoms (Rhee et al., 2005). Children reporting frequent non-specific health complaints in pre-adolescence will present a higher both past and future health care use (Rytter et al., 2020). This problem means that most of the minors suffering from somatic complaints will experience a significantly lower quality of life in all domains (Merlijn et al., 2003).

Nevertheless, these two components do not offer the whole picture of the situation. To foster preadolescents' well-being, certain individual differences based on psychological factors have also to be examined concerning subjective well-being, namely, trait emotional intelligence, self-esteem, and perceived stress. These three factors are strongly intertwined in the process leading to influencing subjective well-being. Trait emotional intelligence is defined as "a constellation of behavioral dispositions and self-perceptions concerning one's ability to recognize, process and utilize emotion-laden information" (Petrides et al., 2004, p. 278). Therefore, subjects with a strong trait emotional intelligence will be able to face negative situations more easily than will subjects with low trait emotional intelligence, consequently perceiving lower levels of stress in these situations. Moreover, the confidence preadolescents have in their abilities will facilitate higher levels of self-esteem (Schutte et al., 2002). In this sense, self-esteem may play a protective role in psychosocial health (Piko et al., 2016). This entire process will contribute to promoting preadolescents' well-being.

Both life satisfaction and somatic complaints are predicted by trait emotional intelligence in adolescents (de la Barrera et al., 2019), with emotional clarity (being able to understand one's own emotions) emerging as the key dimension (Lischetzke and Eid, 2017; PradoGascó et al., 2018; Vergara et al., 2015). Although the dimension of emotional attention also emerges as an outstanding predictor, it is usually a controversial dimension (VeytiaLópez et al., 2019; Villanueva et al., 2017). Some authors defend that it is the combination of high attention and high clarity which is associated with the lowest frequency of somatic complaints (Ballespí et al., 2019).

Moreover, low self-esteem has also been observed to be related to life dissatisfaction (Freire and Tavares, 2011; Moksnes and Espnes, 2013; Rey et al., 2011) and somatic complaints (Aanesen et al., 2017; Piko et al., 2016). The long-term consequences of self-esteem have also been observed beyond adolescence, extending into emerging adulthood (Trzesniewski et al., 2006). Finally, the degree to which situations in one's life are appraised as stressful, that is, perceived stress, was also observed to be associated with subjective well-being indicators, namely, life satisfaction (Abolghasemi and Varaniyab, 2010; Extremera et al., 2009) and somatic complaints (Hjern et al., 2008; Murberg and Bru, 2007).

Some studies have analyzed the interplay of perceived stress with trait emotional intelligence and life satisfaction, showing how stress may buffer the benefits of emotional intelligence on subjective well-being (Rey et al., 2011; Schoeps et al., 2019). The same process applies to the variable self-esteem but with the opposite effect (de la Barrera et al., 2019; Extremera et al., 2009). Nevertheless, the three psychological factors examined in this research were mainly studied separately or in pairs, as 
few studies have included all factors (Extremera et al., 2009; Rey et al., 2011) and, at the same time, their relation to the aforementioned two different types of well-being indicators.

Regarding the studied age range in this research, although fewer studies have examined subjective well-being in preadolescents' psychological adjustment, this age period (1216 years of age) includes several normative challenges that deserve our attention. For instance, the physical, emotional, and cognitive changes taking place in this period, the recent entry into high school (Eriksson and Sellström, 2010), or the identity confusion phase (Erikson, 1968) challenge the preadolescents' daily adjustments. Not in vain, some authors have labeled this period as a "window of opportunity for understanding and impacting health and development in adolescence and beyond" (Dorn et al., 2019 , p. 155). Therefore, the variable age of participant has been included in the predictive models of this study, as well as gender, given the different adaptation patterns that boys and girls from this age seem to present (Eschenbeck et al., 2007; Hampel and Petermann, 2005).

Moreover, in this age period, a wide range of variables present less predictive power, for example in explaining life satisfaction (Joshanloo and Jovanović, 2018), and few studies have examined the long-term adjustment outcomes in longitudinal designs (Gómez-Baya et al., 2017; Resurrección et al., 2014; Salguero et al., 2012). Therefore, longitudinal analyses are needed to determine whether the prediction of subjective well-being by various variables (not only emotional intelligence) is stable over time. To this end, we examined in this study associations separated by a 1-year interval.

Finally, two different analytic strategies will be compared in this work: regression models and a fuzzy-set qualitative comparative analysis (QCA). The regression models are mainly based on the individual contribution of various variables of the study, which do not take into account equifinality, that is, the possibility of the existence of different pathways leading to the same result (Eng and Woodside, 2012; Ragin, 2008). In contrast, qualitative comparative analysis (QCA) is an analytical technique that allows an in-depth analysis of how a series of causal conditions contributes to a given outcome. Instead of depending on the individual contribution of each attribute, the result depends to a greater extent on how these attributes are combined. As stated before, the three psychological factors analyzed here (trait emotional intelligence, self-esteem, perceived stress, as well as gender and age) are strongly intertwined in the process leading to influencing subjective well-being. However, they have been traditionally studied separately. Therefore, this type of strategy, QCA, is a novel method for analyzing complex phenomena in social sciences. Despite wide interest, few psychology studies have used this type of methodology in combination with regression models (EscamillaFajardo et al., 2020; Villanueva et al., 2019).

A study including both types of analytical strategies would, therefore, help enrich the analysis of the current scenario of subjective well-being. Moreover, using several psychological factors as predictors, and the inclusion of both cognitive and affective components of subjective well-being, and their measures in a longitudinal design are the most significant contributions of this study. Therefore, this study aims to analyze the combined contribution of trait emotional intelligence, self-esteem, and perceived stress to various indicators of preadolescents' well-being. We expected that high levels of trait emotional intelligence and self-esteem, and low levels of perceived stress would be negatively associated with somatic complaints, and positively with life satisfaction. We also expected that qualitative comparative analysis (QCA) compared to regression models would provide a complementary and more detailed prediction model of well-being in preadolescents.

\section{Methods}

\section{Participants}

The sample comprised 381 pupils aged from 12 to $16(\mathrm{M}=13.49$ years; $\mathrm{SD}=1.15)$ from the 
Valencian Region in Spain. Among them, 214 were female $(56.1 \%)$. All the pupils attended two public and private high schools $(41.7 \%$ and $58.3 \%$, respectively), located across a range of working to upper-middle-class urban areas that were selected using a convenience sampling method. No variability across schools was observed in students' scores. Participants from $\mathrm{T} 1$ to $\mathrm{T} 2$ were 381 , as only those subjects who participated in both periods were considered.

\section{Measures}

TMMS-24 "Trait Emotional Meta-Mood Scale" was validated in Spain by FernándezBerrocal et al. (2004) and is based on the Trait Meta-Mood Scale by Salovey et al. (1995). The scale assesses meta-knowledge of the three elements: (1) emotional attention, which is the extent to which individuals tend to observe and think about their feelings and moods, (2) emotional clarity, which evaluates the understanding of one's emotional states, and (3) emotional repair, which involves the individual's beliefs regarding the ability to regulate his or her feelings. All 24 items are scored on a scale ranging from 1 to 5 . The TMMS subscales have been demonstrated to have adequate psychometric properties (attention, $\alpha=.90$; clarity, $\alpha=.90$; repair, $\alpha=.86$; Fernández-Berrocal et al., 2004). In this study, reliability was $\alpha=.85$ for attention, $\alpha=.84$ for clarity, and $\alpha=.78$ for repair.

The PSS-4 Perceived Stress Scale (Cohen and Williamson, 1988; Spanish version of Herrero and Meneses, 2006) is a brief version of the Perceived Stress Scale (PSS) (Cohen et al., 1983). This questionnaire comprises four items that evaluate the degree to which individuals believe that their lives have been unpredictable and uncontrollable during the previous month. It has a four-point response scale; a higher score indicates a greater presence of perceived stress. Previous research has demonstrated this scale to be reliable and valid with acceptable alpha values in Spanish children $(\alpha=.68)$, (Herrero and Meneses, 2006). In this study, reliability was $\alpha=.68$.
The Rosenberg Self-Esteem Scale (RSE; Rosenberg, 1965; Spanish sample validation by Rodríguez-Cano et al., 2006) was used to assess self-esteem. This scale is composed of 10 items with a Likert-type response format of 5 alternatives. Five items are written in their positive forms, shaping the positive self-esteem scale, and the other five are in their negative forms, shaping the negative self-esteem scale (Fourchard and Courtinat-Camps, 2013). This instrument has shown good psychometric properties both in its original version and in its Spanish validation $(\alpha=.86)$. In the present study, it shows good reliability ( $\alpha=.85)$.

The Satisfaction with Life Scale (SWLS) (Diener et al., 1985), adapted to a Spanish context (Atienza et al., 2000), measures the cognitive evaluation or judgment of one's overall life and consists of five items. Each item is answered on a 7-point Likert-type scale, and all the items are summed to form a general score of satisfaction with life. Previous studies (Atienza et al., 2000; Diener et al., 1985) have shown this scale to have adequate psychometric properties $(\alpha=.87)$, which was also the case in this study $(\alpha=.88)$.

The Somatic Complaint List (SCL; Rieffe et al., 2006; adapted by Górriz et al., 2015) comprises 11 items that are answered on a three-point Likert scale. The participants should indicate how often they experience somatic symptoms such as stomachache, tiredness, or back pain. This questionnaire has been shown to have adequate psychometric properties (Rieffe et al., 2009). In this study, the consistency was $\alpha=.81$.

\section{Procedure}

The study is a longitudinal prospective design that provides information about the development of possible outcomes over time. In this sense, it is important to measure the psychological predictors before the development of the negative and positive outcomes (somatic complaints and life satisfaction), to avoid retrospective bias and draw possible causal conclusions (Farrington and Loeber, 2014). 
Table I. Main descriptors and calibration values.

\begin{tabular}{lcccccccc}
\hline & SCL & SWLS & Age & EA & EC & ER & Self-esteem & Perceived stress \\
\hline M & 1.45 & 26.83 & 13.49 & 24.42 & 25.25 & 27.32 & 31.91 & 8.24 \\
SD & .34 & 5.96 & 1.15 & 6.86 & 6.59 & 6.50 & 4.95 & 2.04 \\
Min & 1 & 5 & 12 & 4 & 8 & 10 & 13 & 4 \\
Max & 2.91 & 35 & 16 & 40 & 40 & 40 & 40 & 14 \\
Calibration values & & & & & & & \\
PI0 & 1.09 & 18 & 12 & 16 & 17 & 19 & 25 & 6 \\
P50 & 1.36 & 28 & 14 & 24 & 25 & 27 & 32 & 8 \\
P90 & 1.95 & 34 & 15 & 33.50 & 34 & 36 & 38 & 11 \\
\hline
\end{tabular}

Note. M: mean; SD: standard deviation; Min: minimum; Max: maximum; PI0: 10th percentile; P50: 50th percentile; P90: 90th percentile. SCL: Somatic Complaints; SWLS: Satisfaction with Life Scale; EA: Emotional Attention; EC: Emotional Clarity; ER: Emotional Repair.

The necessary consent of the county government, schools, parents, and the ethical university commission was obtained before the adolescents were recruited. The adolescents completed the questionnaires collectively during their usual school hours. The same two researchers were always present during the evaluation. All participants who did not answer $100 \%$ of the questionnaire items were removed from the study $(n=14)$. To achieve the objectives of the present study, data were obtained at two different points in time: independent variables were measured first, and dependent variables were measured after 1 year.

\section{Data analysis}

First, descriptive analyses of participants were performed, and calibration values were estimated; the linear relationships between the variables under study were then analyzed using Pearson correlations and multiple hierarchical linear regressions. All these analyses were performed with the IBM SPSS Statistics 24 software package (IBM Corporation). Afterward, fuzzy-set qualitative comparative analysis (fsQCA) was performed. During the fuzzy-set qualitative comparative analysis, all the missing data were deleted, and all the constructs (variables) were recalibrated considering three thresholds: 10th, 50th and 90th percentiles (Navarro-Mateu et al., 2019; Woodside, 2013). Finally, tests of necessary and sufficient conditions evaluate the effect of various variables on well-being indicators. fsQCA 3.0 software (Claude and Christopher, 2014) provides the tool to perform fsQCA.

\section{Results}

Main descriptors, calibration values, and correlations between the study variables are presented in Tables 1 and 2. About correlation analyses, significant negative correlations were found between the subjective well-being indicators (life satisfaction and somatic complaints $),(r=-.38)$, significant positive correlations between trait emotional components, self-esteem and life satisfaction (ranging from .23 to .37), and negative with somatic complaints (ranging from . -12 to . -28 ). Significant negative correlations of perceived stress with life satisfaction $(r=-.28)$, and positive with somatic complaints $(r=.25)$ were also observed. Finally, significant negative correlations between perceived stress and self-esteem/trait emotional intelligence (except for attention), ranging from -.34 to -.54 , were found.

Hierarchical regression models are shown in Table 3. Two multiple hierarchical linear analyses with four steps were performed, one to predict levels of somatic complaints (SCL) and another to determine levels of life satisfaction (SWLS). In the first step the socio-demographic variables (age and sex) were included, then in step two, the variables of emotional intelligence 
Table 2. Pearson correlations between the study variables.

\begin{tabular}{llllllll}
\hline & $\mathrm{I}$ & 2 & 3 & 4 & 5 & 6 & 7 \\
\hline I. SCL & $\mathrm{I}$ & & & & & & \\
2. SWLS & $-.38^{* *}$ & $\mathrm{I}$ & & & & & \\
3. Age & .06 & $-.13^{*}$ & $\mathrm{I}$ & & & & \\
4. EA & $.12^{*}$ & .06 & $.16^{* *}$ & $\mathrm{I}$ & & & \\
5. EC & $-.12^{*}$ & $.23^{* *}$ & -.032 & $.32^{* *}$ & $\mathrm{I}$ & & \\
6. ER & $-.14^{* *}$ & $.31^{* *}$ & -.054 & $.24^{* *}$ & $.47^{* *}$ & $\mathrm{I}$ & \\
7. Self-esteem & $-.28^{* *}$ & $.37^{* *}$ & -.015 & .04 & $.32^{* *}$ & $.35^{* *}$ & $\mathrm{I}$ \\
8. Perceived stress & $.25^{* *}$ & $-.31^{* *}$ & .094 & .08 & $-.36^{* *}$ & $-.34^{* *}$ & $-.54^{* *}$ \\
\hline
\end{tabular}

Note. ${ }^{*} p \leqslant .05 ; *_{p}^{*} \leqslant .01 ; * * * p \leqslant .001$. SCL: Somatic Complaints; SWLS: Satisfaction with Life Scale; EA: Emotional Attention; EC: Emotional Clarity; ER: Emotional Repair.

Table 3. Hierarchical regressions for the prediction of SCL and SWLS.

\begin{tabular}{|c|c|c|c|c|}
\hline \multirow{2}{*}{$\begin{array}{l}\text { Variable } \\
\text { Predictors }\end{array}$} & \multicolumn{2}{|l|}{$\mathrm{SCL}$} & \multicolumn{2}{|l|}{ SWLS } \\
\hline & $\Delta \mathrm{R}^{2}$ & $\beta$ & $\Delta \mathrm{R}^{2}$ & $\beta$ \\
\hline Step I & $.02 *$ & & $.02 *$ & \\
\hline Sex & & $.12 *$ & & .07 \\
\hline Age & & .06 & & $-.14 * *$ \\
\hline Step 2 & $.05^{* * *}$ & & $.11 * * *$ & \\
\hline Sex & & .08 & & $.11 *$ \\
\hline Age & & .03 & & $-.11 *$ \\
\hline Emotional attention & & $.17^{* *}$ & & -.07 \\
\hline Emotional clarity & & $-.13 *$ & & $.15 * *$ \\
\hline Emotional repair & & -.11 & & $.26 * * *$ \\
\hline Step 3 & $.05 * * *$ & & $.05 * * *$ & \\
\hline Sex & & .09 & & $.10 *$ \\
\hline Age & & .03 & & $-.11 *$ \\
\hline Emotional attention & & $.13^{*}$ & & -.03 \\
\hline Emotional clarity & & -.06 & & .07 \\
\hline Emotional repair & & -.05 & & $.19 * * *$ \\
\hline Self-esteem & & $-.24 * * *$ & & $.26 * * *$ \\
\hline Step 4 & .01 & & .01 & \\
\hline Sex & & .08 & & $.11 *$ \\
\hline Age & & .02 & & $-.10 *$ \\
\hline Emotional attention & & $.11 *$ & & -.01 \\
\hline Emotional clarity & & -.04 & & .05 \\
\hline Emotional repair & & -.04 & & $.18^{* *}$ \\
\hline Self-esteem & & $-.20 * * *$ & & $.21 * * *$ \\
\hline Perceived stress & & .09 & & -.11 \\
\hline Total $R_{\text {adjusted }}^{2}$ & $.10 * * *$ & & $.18 * * *$ & \\
\hline
\end{tabular}

Note. ${ }^{*} p \leqslant .05 ; * *_{p} \leqslant .01 ; * * * p \leqslant .001$. SCL: Somatic Complaints; SWLS: Satisfaction with Life Scale.

were considered, in step three, self-esteem, and in the last step, the level of perceived stress was added. The rationale for the order of introduction of the variables was the theoretical framework stated in the Introduction: levels of trait emotional intelligence and self-confidence 
Table 4. Necessity analysis for SCL and SWLS.

\begin{tabular}{|c|c|c|c|c|c|c|c|c|}
\hline & \multicolumn{2}{|l|}{$\mathrm{SCL}$} & \multicolumn{2}{|l|}{$\sim S C L$} & \multicolumn{2}{|l|}{ SWLS } & \multicolumn{2}{|c|}{$\sim S W L S$} \\
\hline & Cons & Cov & Cons & Cov & Cons & Cov & Cons & Cov \\
\hline Girl & .63 & .50 & .53 & .50 & .59 & .52 & .56 & .48 \\
\hline Boy & .37 & .40 & .47 & .60 & .41 & .49 & .44 & .51 \\
\hline Age (Older) & .56 & .61 & .50 & .65 & .48 & .59 & .58 & .68 \\
\hline Age (Younger) & .68 & .53 & .70 & .65 & .74 & .64 & .65 & .55 \\
\hline Perceived stress & .70 & .63 & .55 & .58 & .55 & .55 & .72 & .70 \\
\hline$\sim$ Perceived stress & .54 & .50 & .65 & .72 & .70 & .72 & .54 & .54 \\
\hline Self-esteem & .58 & .50 & .70 & .72 & .73 & .70 & .58 & .54 \\
\hline$\sim$ Self-esteem & .68 & .66 & .51 & .59 & .52 & .57 & .68 & .71 \\
\hline Emotional attention & .63 & .57 & .60 & .64 & .63 & .63 & .60 & .58 \\
\hline$\sim$ Emotional attention & .60 & .56 & .60 & .66 & .59 & .60 & .62 & .62 \\
\hline Emotional clarity & .56 & .51 & .65 & .70 & .66 & .67 & .56 & .56 \\
\hline$\sim$ Emotional clarity & .68 & .62 & .55 & .60 & .57 & .57 & .67 & .66 \\
\hline Emotional repair & .58 & .53 & .64 & .69 & .69 & .70 & .55 & .54 \\
\hline Emotional repair & .66 & .61 & .56 & .61 & .54 & .55 & .69 & .68 \\
\hline
\end{tabular}

Note: SCL: Somatic Complaints; SWLS: Satisfaction with Life Scale; Cons: consistency; Cov: coverage; : absence of condition; condition needed: consistency $\geqslant .90$.

in the children's abilities would lead to perceive stress in different grades, therefore allowing somatic complaints or life satisfaction to appear.

In general, regarding SCL prediction, it seems that the inclusion of steps two and three improved the model by $5 \%$ each, while the inclusion of step four introduced hardly any changes in the model $(0.5 \%)$. In terms of SWLS prediction, the inclusion of step two improved the model by $11 \%$, while the inclusion of steps three and four slightly produced improvements in the model with a change of $5 \%$ and $0.8 \%$, respectively.

Sex, emotional attention and clarity, and self-esteem were the significant factors that contributed to explaining $10 \%$ of the somatic complaints' variance. In the case of life satisfaction, sex, age, emotional clarity and repair, and self-esteem explained $18 \%$ of the variance. In contrast, perceived stress did not appear as a significant variable in any of the regression models.

Afterward, to obtain a complementary view of the relations between variables, the prediction of somatic complaints and life satisfaction was analyzed using fsQCA models.
We started by testing whether any of the causal conditions could be considered a necessary condition (Table 4) and then we analyzed sufficient conditions for these variables (Table 5).

A condition is considered necessary if it must always be present for the result to occur. In this sense, none of the variables is a necessary condition, as all consistency values are under .90 (Ragin, 2008). The sufficient conditions are those of being a girl, being older, the presence of perceived stress, and the presence of emotional attention, while the absence of self-esteem, the absence of emotional clarity and emotional repair were associated with high levels of somatic complaints and low levels of satisfaction with life. The opposite was observed for the prediction of low levels of somatic complaints and high levels of life satisfaction.

The three most important combinations for high levels of somatic complaints were the interaction between low level of emotional clarity, low level of self-esteem, high level of perceived stress and being a girl (raw coverage $=.31$ ), the interaction between a high level of emotional repair, low level of 
Table 5. Summary of the three main sufficient conditions for the intermediate solution of the prediction of SCL and SWLS.

\begin{tabular}{|c|c|c|c|c|c|c|c|c|c|c|c|c|}
\hline \multirow[t]{3}{*}{ Frequency cutoff: I } & \multirow{2}{*}{\multicolumn{3}{|c|}{$\begin{array}{l}\text { SCL } \\
\text { Consistency } \\
\text { cutoff: .85 }\end{array}$}} & \multirow{2}{*}{\multicolumn{3}{|c|}{$\begin{array}{l}\sim \mathrm{SCL} \\
\text { Consistency } \\
\text { cutoff: .84 }\end{array}$}} & \multirow{2}{*}{\multicolumn{3}{|c|}{$\begin{array}{l}\text { SWLS } \\
\text { Consistency } \\
\text { cutoff: .85 }\end{array}$}} & \multirow{2}{*}{\multicolumn{3}{|c|}{$\begin{array}{l}\sim \text { SWLS } \\
\text { Consistency } \\
\text { cutoff: .85 }\end{array}$}} \\
\hline & & & & & & & & & & & & \\
\hline & I & 2 & 3 & I & 2 & 3 & I & 2 & 3 & I & 2 & 3 \\
\hline Girl & - & - & - & & & 0 & - & & & & & \\
\hline Age (Older) & $\bullet$ & ○ & $\bullet$ & & ○ & & O & 0 & O & & & - \\
\hline Perceived stress & & & & 0 & & 0 & & O & O & - & - & 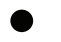 \\
\hline Self-esteem & 0 & 0 & O & 0 & ○ & $\bullet$ & $\bullet$ & & $\bullet$ & O & $\bigcirc$ & O \\
\hline Emotional attention & & & & O & ○ & & & & & & & \\
\hline Emotional clarity & O & & O & 0 & & & & ○ & - & & - & \\
\hline Emotional repair & & 0 & & & - & $\bullet$ & & ○ & & 0 & & \\
\hline Raw coverage & .31 & .31 & .23 & .29 & .25 & .22 & .34 & .38 & .38 & .47 & .34 & .38 \\
\hline Unique coverage & .02 & .02 & .00 & .02 & .04 & .00 & .04 & .02 & .02 & .01 & .01 & .00 \\
\hline Consistency & .81 & .81 & .85 & .85 & .84 & .84 & .77 & .87 & .85 & .81 & .82 & .83 \\
\hline Overall solution consistency & & & .75 & & & .79 & & & .75 & & & .76 \\
\hline Overall solution coverage & & & .38 & & & .66 & & & .70 & & & .69 \\
\hline
\end{tabular}

Note: SCL: Somatic Complaints; SWLS: Satisfaction with Life Scale. $=$ presence of condition, $\bigcirc=$ absence of condition, $\sim=$ absence of condition. All sufficient conditions are adequate; the raw coverage is between .25 and .65 ;

Expected vector for SCL and $\sim$ SWLS: I, I, I,0, I,0,0 (0: absent; I: present).

Expected vector for $\sim S C L$ and SWLS: 0,0,0,I,0,I,I.

self-esteem, high level of perceived stress and being a girl, that also accounted for $31 \%$ of the data, and, finally, the interaction between low level of emotional clarity, low level of selfesteem, being older and being a girl (raw coverage $=.23$ ). On the other hand, considering the low levels of somatic complaints, the most important three combinations were the interaction between high levels of emotional clarity, low levels of emotional attention, high levels of self-esteem, and low level of perceived stress (raw coverage $=.29$ ), the interaction between high levels of emotional repair, high levels of emotional attention, high levels of self-esteem, and being older, that accounted for $25 \%$ of the data, and, finally, the interaction between a high level of emotional repair, high level of selfesteem, low level of perceived stress, and being a boy (raw coverage $=.22$ ).

Regarding life satisfaction, the three most important combinations were, in the case of high levels, the interaction between high levels of self-esteem, being younger, and being a girl $($ raw coverage $=.34)$, the interaction between a high level of emotional repair, high level of emotional clarity, low level of perceived stress, and being younger (raw coverage $=.38$ ), and the interaction between a high level of emotional clarity, high level of self-esteem, low level of perceived stress, and being younger (raw coverage $=.38$ ). In contrast, considering the low levels of life satisfaction, the three most important combinations were the interaction between low level of emotional repair, low level of self-esteem, and high level of perceived stress (raw coverage $=.47$ ), the interaction between a high level of emotional clarity, low level of self-esteem, and high level of perceived stress (raw coverage $=.34$ ), and finally, the interaction between low level of selfesteem, high level of perceived stress, and being older ( raw coverage $=.38$ ).

\section{Discussion}

The objective of this study was to analyze the combined contribution of trait emotional intelligence, self-esteem, and perceived stress 
to different positive and negative functioning outcomes in preadolescence. We expected that high levels of trait emotional intelligence and self-esteem, and low levels of perceived stress would be negatively associated with somatic complaints and positively with life satisfaction. This hypothesis was supported by the results obtained in both analytic strategies.

Consistently with previous studies that analyzed these variables separately (Aanesen et al., 2017; Extremera et al., 2009; Prado-Gascó et al., 2018), the present study showed that trait emotional intelligence (particularly emotional clarity), self-esteem and low perceived stress were related in the expected direction to higher life satisfaction and somatic complaints. The inclusion of self-esteem and perceived stress helps improve the prediction of somatic complaints and life satisfaction beyond the contribution of trait EI.

In the regression models, emotional attention and clarity appeared as predictors of somatic complaints (with positive and negative relations, respectively), and clarity and repair as predictors of life satisfaction. However, only clarity emerges as significant in the fuzzy models, in combination with other variables (stress and self-esteem). Unsurprisingly in this age range, the perceived ability to discriminate clearly among feelings seems to be the most important emotional component concerning subjective well-being. This result shows the primacy of this variable versus the rest of the components of trait emotional intelligence, supporting previous studies (Lischetzke and Eid, 2017; Prado-Gascó et al., 2018). The possible explanation for this primacy of clarity may be related to the fact that those with higher ability to identify their emotional states (both types and causes), may better select and identify the adequate regulation strategy, therefore being more effective in affect regulation, and as a result, enhancing subjective well-being (Lischetzke and Eid, 2017). If we think about the controversial role played by emotional attention on subjective well-being (PradoGascó et al., 2018), or the last position of emotional regulation in the process of daily adaptation (Gross, 2015), it seems logical that the component of emotional clarity emerges as the most outstanding component. On the other hand, attention appeared with its individual contribution in the regression models but not in the fuzzy models, in which the multiple contributions of all the variables are enhanced. A possible explanation may be that the already known negative effect of emotional attention on subjective well-being was inhibited when clarity and repair were also included, as observed in previous studies (Ballespí et al., 2019; Vergara et al., 2015). In contrast, the opposite pattern applies to the variable of perceived stress. This variable appears as significant for both wellbeing indicators in the fuzzy models but not in the regression models. Maybe the variable perceived stress by itself does not contribute to impact well-being as strongly as perceived stress in combination with other variables (such as emotional clarity). This combination may lead to low levels of life satisfaction, showing specific effects, and supporting the theoretical pathway presented in this study for subjective well-being. Clarity and self-esteem were the only components that appeared as significant in both analytic strategies (regression and QCA), showing the importance of their contributions either individually or in combination with other variables.

It is remarkable that both well-being indicators (life satisfaction and somatic complaints), even though one is cognitive in nature, and the other is affective, are explained by the combination of the same variables in the fuzzy models: emotional clarity, self-esteem, and perceived stress. These results support the idea that, first, somatic complaints may be considered a valid indicator of subjective well-being in preadolescents, associated with the affective component of this concept. Second, although subjective well-being indicators are independent and may be assessed individually (Diener et al., 2003), they are closely related phenomena and may share a common variance. Although both variables, somatic complaints, and life satisfaction, seem to act as unpleasant and pleasant valence indicators of well-being, 
we still have to be cautious about the role of somatic complaints, as further research is needed to support it as a valid and long-term indicator.

A special comment concerns the fact that even individual variables measured one year before they appeared to be associated with long-term subjective well-being. This finding may indicate that trait emotional intelligence, self-esteem and perceived stress are long-term valid predictors of subjective well-being in preadolescents, although the specific emotional component seems to change depending on the type of outcome (attention and clarity for somatic complaints, and clarity and repair for life satisfaction). For instance, Salguero et al. (2012) observed that attention and repair were the key components predicting anxiety, depression, and social stress one year later. Additionally, Gómez-Baya et al. (2017) found that attention and clarity were associated with depressive symptoms two years later. However, in this study, clarity was the most important component associated with somatic complaints and life satisfaction one year later.

We also expected the qualitative comparative analysis (QCA), compared to regression models, to provide a complementary and more detailed prediction model of well-being in adolescents. This hypothesis was also supported by the obtained results, as found in the few studies combining both types of analyses (EscamillaFajardo et al., 2020; Villanueva et al., 2019). When the two methodologies are compared, QCA models present greater predictive value than do regression models, include variables that, despite their importance, go unnoticed if we focus only on regression models (e.g. perceived stress) and are important predictors when interacting with other conditions. Although numerous studies have supported some of these pathways between variables, for example, adolescents with low trait emotional intelligence presenting more somatic complaints (Prado-Gascó et al., 2018) or low selfesteem being related to life dissatisfaction (Rey et al., 2011), it is also true that most studies do not consider the interaction between these individual characteristics. Rather than depending on the individual contribution of each attribute, the results depend to a greater extent on how these attributes are combined.

In the QCA models, a poor understanding of one's emotions, low self-esteem, a high perception of stress, and the female gender were related to high levels of somatic complaints. For the second well-being indicator, a rich understanding of one's emotions, high selfesteem, combined with low levels of perceived stress and being young were associated with high life satisfaction. As was observed, this type of analysis allows for greater horizontal complexity than that of regression models. Moreover, these combinations of variables help to create specific customized interventions including the key concepts (e.g. clarity for emotional concepts) or the suitable gender and age range (girls for somatic complaints, or young adolescents for life dissatisfaction).

Finally, some limitations of the current study must be mentioned. One limitation was that the data were collected only through self-report measures. Further research should include additional subjective and objective indicators of well-being, such as medical checkups, physiological measures of stress, or parent reports, to obtain a more realistic picture of the situation. The second limitation concerns the sample, in terms of both the sampling procedures, which were not probabilistic, and its geographical location. In the future, a stratified probability sampling considering different geographical areas would improve the possible generalization of the data.

Despite these limitations, the results of this study support a specific pathway to improve the well-being of preadolescents: developing a clear understanding of their emotional experiences will lead to low perceived stress and the enhancement of self-esteem, as feelings of effective control of a negative situation will emerge more easily. An important aspect of intervention programs for adolescents that are focused on decreasing somatic complaints (which is particularly beneficial for girls) and promoting life satisfaction (which is particularly 
suitable for the older preadolescents) may be the understanding that personal resources (such as emotional intelligence or self-esteem) can be used or enhanced to improve the individuals' well-being situation. As a result, preadolescents may become an active part of their well-being management instead of being solely dependent on the unequivocal result of an external event (e.g. a negative situation).

\section{Acknowledgements}

We thank the participating students, parents, teaching and administrative staff of the participating schools for their cooperation and support.

\section{Data available}

The data that support the findings of this study are available from the corresponding author upon reasonable request.

\section{Declaration of conflicting interests}

The author(s) declared no potential conflicts of interest with respect to the research, authorship, and/or publication of this article.

\section{Ethical commission}

The necessary consent of the county government (Conselleria d'Educació, Investigació, Cultura i Esport), schools, parents and the ethical university commission of Valencia University (code H1385330676977) was obtained before the adolescents were recruited.

\section{Funding}

The author(s) disclosed receipt of the following financial support for the research, authorship, and/or publication of this article: The research reported in this article was supported by grants from the Spanish Ministry of Economy and Competitiveness (PSI2013-43943-R) and the Research State Agency -AEI- of the Spanish Ministry of Science, Innovation and Universities (PSI2017-84005-R) and the European Regional Development Fund (FEDER) from the European Union.

\section{ORCID iD}

Montoya-Castilla (iD https://orcid.org/0000-0003 $-2536-2019$

\section{References}

Aanesen F, Meland E and Torp S (2017) Gender differences in subjective health complaints in adolescence: The roles of self-esteem, stress from schoolwork and body dissatisfaction. Scandinavian Journal of Public Health 45(4): 389-396.

Abolghasemi A and Taklavi Varaniyab S (2010) Resilience and perceived stress: Predictors of life satisfaction in students of success and failure. Procedia-Social and Behavioral Sciences 5: 748-752.

Atienza FL, Pons D, Balaguer I, et al. (2000) Propiedades psicométricas de la escala de satisfacción con la vida en adolescentes. Psicothema 12: 314-319.

Ballespí S, Vives J, Alonso N, et al. (2019) To know or not to know? Mentalization as protection from somatic complaints. PLoS One 14(5): e0215308.

Claude R and Christopher R (2014) Acq [Computer Programme]. Houston, TX: University of Houston-Downtown.

Cohen S and Williamson G (1988) Perceived stress in a probability sample of the United States. In: Spacapan S and Oskamp S (eds) The Social Psychology of Health: Claremont Symposium on Applied Social Psychology. Newbury Park, CA: Sage, pp. 31-67.

Cohen S, Kamarck T and Mermelstein R (1983) A global measure of perceived stress. Journal of Health and Social Behavior 24(4): 385-396.

Cummins RA and Nistico H (2002) Maintaining life satisfaction: The role of positive cognitive bias. Journal of Happiness Studies 3(1): 37-69.

de la Barrera U, Schoeps K, Gil-Gómez J-A, et al. (2019) Predicting adolescent adjustment and well-being: The interplay between socioemotional and personal factors. International Journal of Environmental Research and Public Health Article 16(4650).

de la Barrera U, Villanueva L and Prado-Gascó V (2019) Emotional and personality predictors that influence the appearance of somatic complaints in children and adults. Psicothema 31(4): 407-413.

Diener E (2009) Subjective well-being. In: Diener E (ed.) The Science of Well-being. Dordrecht: Springer, pp. 11-58.

Diener E, Emmons RA, Larsen RJ, et al. (1985) The satisfaction with life scale. Journal of Personality Assessment 49: 71-75. 
Diener E, Oishi S and Lucas RE (2003) Personality, culture, and subjective well-being: Emotional and cognitive evaluations of life. Annual Review of Psychology 54: 403-425.

Diener E, Scollon CN and Lucas RE (2009) The evolving concept of subjective well-being: The multifaceted nature of happiness. In: Diener E (ed.) Social Indicators Research Series: Vol. 39. Assessing Well-Being: The Collected Works of Ed Diener. New York, NY: Springer Science + Business Media, pp. 67-100.

Dorn LD, Hostinar CE, Susman EJ, et al. (2019) Conceptualizing puberty as a window of opportunity for impacting health and well-being across the life span. Journal of Research on Adolescence 29(1): 155-176.

Eng S and Woodside AG (2012) Configural analysis of the drinking man: Fuzzy-set qualitative comparative analyses. Addictive Behaviors 37(4): 541-543.

Eriksson EH (1968) Identity: Youth and Crisis. New York: W. W. Norton \& Company.

Eriksson U and Sellstrom E (2010) School demands and subjective health complaints among Swedish schoolchildren: a multilevel study. Scandinavian Journal of Public Health 38(4): 344-350.

Escamilla-Fajardo P, Núñez-Pomar JM, PradoGascó VJ, et al. (2020) HRM versus QCA: What affects the organizational climate in sports organizations? Sport in Society 23(2): 264-279.

Eschenbeck H, Kohlmann CW and Lohaus A (2007) Gender differences in coping strategies in children and adolescents. Journal of Individual Differences 28(1): 18-26.

Extremera N, Durán A and Rey L (2009) The moderating effect of trait meta-mood and perceived stress on life satisfaction. Personality and Individual Differences 47(2): 116-121.

Farrington DP and Loeber R (2014) Establishing causes of offending in longitudinal and experimental studies. In: Bruinsma $\mathrm{G}$ and Weisburd D (eds), Encyclopedia of Criminology and Criminal Justice. New York: Springer, pp. 1368-1377.

Fernández-Berrocal P, Extremera N and Ramos N (2004) Validity and reliability of the Spanish modified version of the Trait Meta-Mood Scale. Psychological Reports 94: 751-755.

Fourchard F and Courtinat-Camps A (2013) L'estime de soi globale et physique à l'adolescence.
Neuropsychiatrie De l'Enfance Et De

l'Adolescence 61(6): 333-339.

Freire T and Tavares D (2011) Influence of selfesteem and emotion regulation in subjective and psychological well-being of adolescents: Contributions to clinical psychology. Archives of Clinical Psychiatry (São Paulo) 38(5): 184188.

Gómez-Baya D, Mendoza R, Paino S, et al. (2017) Perceived emotional intelligence as a predictor of depressive symptoms during mid-adolescence: A two-year longitudinal study on gender differences. Personality and Individual Differences, 104: 303-312.

Górriz AB, Prado-Gascó VJ, Villanueva L, et al. (2015) Psychometric properties of the Somatic Complaints Scale in Spanish children and adults. Psicothema 27(3): 269-276.

Gross JJ (2015) Emotion regulation: Current status and future prospects. Psychological Inquiry 26: $1-26$.

Hampel P and Petermann F (2005) Age and gender effects on coping in children and adolescents. Journal of Youth and Adolescence 34(2): 73-83.

Herrero J and Meneses J (2006) Short Web-based versions of the perceived stress (PSS) and Center for Epidemiological Studies-Depression (CESD) Scales: A comparison to pencil and paper responses among Internet users. Computers in Human Behavior 22(5): 830-846.

Hjern A, Alfven G and Ostberg V (2008) School stressors, psychological complaints and psychosomatic pain. Acta Paediatrica 97(1): 112-117.

Joshanloo M and Jovanović V (2018) Similarities and differences in predictors of life satisfaction across age groups: A 150-countrystudy.Journal of Health Psychology. Epub ahead of print 19 December 2018. DOI: $10.1177 / 1359105318819054$.

Lischetzke T and Eid M (2017) The functionality of emotional clarity: A process-oriented approach to understanding the relation between emotional clarity and well-being. In: Robinson MD and Eid M (eds), The Happy Mind: Cognitive Contributions to Well-being, pp. 371-388.

Merlijn VPBM, Hunfeld JAM, van der Wouden JC, et al. (2003). Psychosocial factors associated with chronic pain in adolescents. Pain 101(12): $33-43$.

Miers AC, Rieffe C, Terwogt MM, et al. (2007) The relation between anger coping strategies, anger mood and somatic complaints in children 
and adolescents. Journal of Abnormal Child Psychology 35(4): 653-664.

Moksnes UK and Espnes GA (2013) Self-esteem and life satisfaction in adolescents-gender and age as potential moderators. Quality of Life Research: An International Journal of Quality of Life Aspects of Treatment, Care and Rehabilitation 22(10): 2921-2928.

Murberg TA and Bru E (2007) The role of neuroticism and perceived school-related stress in somatic symptoms among students in Norwegian junior high schools. Journal of Adolescence 30(2): 203-212.

Navarro-Mateu D, Franco-Ochoa J, Valero-Moreno $\mathrm{S}$, et al. (2019) To be or not to be an inclusive teacher: Are empathy and social dominance relevant factors to positive attitudes towards inclusive education? PLoS One 14(12): e0225993.

Pavot W and Diener E (1993) Review of the Satisfaction With Life Scale. Psychological Assessment 5(2): 164-172.

Petrides KV, Frederickson N and Furnham A (2004) The role of trait emotional intelligence in academic performance and deviant behavior at school. Personality and Individual Differences 36: 277-293.

Piko BF, Varga S and Mellor D (2016) Are adolescents with high self-esteem protected from psychosomatic symptomatology? European Journal of Pediatrics 175(6): 785-792.

Prado-Gascó V, Villanueva L and Górriz A (2018) Trait emotional intelligence and subjective well-being in adolescents. Psicothema 30(3): 310-315.

Ragin CC (2008) Redesigning Social Inquiry: Fuzzy Sets and Beyond. Chicago: University of Chicago Press.

Resurrección DM, Salguero JM and Ruiz-Aranda D (2014) Emotional intelligence and psychological maladjustment in adolescence: A systematic review. Journal of Adolescence 37(4): 461-472.

Rey L, Extremera N and Pena M (2011) Perceived emotional intelligence, self-esteem and life satisfaction in adolescents. Psychosocial Intervention 20(2): 227-234.

Rhee H, Holditch-Davis D and Miles MS (2005) Patterns of physical symptoms and relationships with psychosocial factors in adolescents. Psychosomatic Medicine 67(6): 1006-1012.

Rieffe C, Oosterveld $\mathrm{P}$ and Meerum-Terwogt M (2006) An alexithymia questionnaire for children: Factorial and concurrent validation results. Personality and Individual Differences 40: 123-133.

Rieffe C, Villanueva L, Adrián JE, et al. (2009) Quejas somáticas, estados de ánimo y conciencia emocional en adolescentes [Somatic complaints, moods and emotional awareness in adolescents]. Psicothema 21(3): 459-464.

Rodríguez-Cano T, Beato-Fernandez L and Llario AB (2006) Body dissatisfaction as a predictor of self-reported suicide attempts in adolescents: A Spanish community prospective study. Journal of Adolescent Health 38: 684-688.

Rosenberg R (1965) Society and the Adolescent SelfImage. Princeton: NJ: Princeton University Press.

Rytter D, Rask CU, Vestergaard CH, et al. (2020) Non-specific health complaints and self-rated health in pre-adolescents; Impact on primary health care use. Scientific Reports 10(1): 1-9.

Salguero JM, Palomera R and Fernández-Berrocal P (2012) Perceived emotional intelligence as predictor of psychological adjustment in adolescents: A 1-year prospective study. European Journal of Psychology of Education 27(1): 21-34.

Salovey P, Mayer JD, Goldman SL, et al. (1995). Emotional attention, clarity, and repair: Exploring emotional intelligence using the Trait Meta-Mood Scale. In: Pennebaker JW (ed), Emotion, Disclosure, \& Health. Washington, DC: American Psychological Association, pp. 125-154.

Sánchez P and Barrio A (2012) Trastornos psicosomáticos [Psychosomatic disorders]. Pediatría Integral XVI(9): 700-706.

Schoeps K, Montoya-Castilla I and Raufelder D (2019) Does stress mediate the association between emotional intelligence and life satisfaction during adolescence? Journal of School Health 89(5): 354-364.

Schutte NS, Malouff JM, Simunek M, et al. (2002). Characteristic emotional intelligence and emotional well-being. Cognition and Emotion 16(6): 769-785.

Trzesniewski KH, Donnellan MB, Moffitt TE, et al. (2006) Low self-esteem during adolescence predicts poor health, criminal behavior, and limited economic prospects during adulthood. Developmental Psychology 42(2): 381-390.

Vergara AI, Alonso-Alberca N, SanJuan C, et al. (2015). Be water: Direct and indirect relations between perceived emotional intelligence and subjective well-being. Australian Journal of Psychology 67(1): 47-54. 
Veytia-López M, Calvete E, Sánchez-Álvarez N, et al. (2019) Relationship between stressful life events and emotional intelligence in Mexican adolescents: Male vs. female comparative study. Salud Mental 42(6): 261-268.

Villanueva L and Górriz AB (2014) La conciencia emocional y su relación con el bienestar infantil [Emotional awareness and its relation to child wellbeing]. In: González R and Villanueva L (eds), Recursos para educar en emociones. De la teoría a la acción [Resources to educate in emotions. From theory to practice]. Madrid: Pirámide, pp. 151-201.

Villanueva L, Montoya-Castilla I and Prado-Gasco $\mathrm{V}$ (2017) The importance of trait emotional intelligence and feelings in the prediction of perceived and biological stress in adolescents: Hierarchical regressions and fsQCA models. Stress 20(4): 355-362.

Villanueva L, Valero-Moreno S, Cuervo K, et al. (2019). Sociodemographic variables, risk factors, and protective factors contributing to youth recidivism. Psicothema 31(2): 128-133.

Woodside AG (2013) Moving beyond multiple regression analysis to algorithms: Calling for adoption of a paradigm shift from symmetric to asymmetric thinking in data analysis and crafting theory. Journal of Business Research 66(4): 463-472. 